\title{
Wound Complications and Treatment of the Infected Implantable Cardioverter Defibrillator Generator
}

\author{
Sanjay Gupta, M.D., Christopher D. Prevel, M.D., Kenneth Shaheen, M.D., \\ Edwin Wilkens, M.D., David J. Smith, Jr., M.D., Marvin M. Kirsh, M.D.," \\ Steven F. Bolling, M.D., ${ }^{*}$ and Riley S. Rees, M.D. \\ Department of Surgery, Sections of Plastic and Reconstructive Surgery and \\ *Thoracic Surgery, University of Michigan Hospitals, Ann Arbor, Michigan
}

\begin{abstract}
Since 1980, the automatic implantable cardloverter defibrillator (ICD) has evolved as effective therapy for prevention of sudden cardiac death following documented sustained ventricular tachycardia or fibrillation. During a 5-year period, 412 ICD devices were implanted at the University of Michigan Hospitals with a wound complication rate of $4.1 \%$. In this group, there were 13 infections, 3 erosions of the generator pocket, and 1 wound hematoma. Of the 16 patients with infection or erosion, 12 patients were treated with a rectus abdominis muscle flap closure and 4 with ICD generator removal. In $83 \%(n=12)$ of the muscle flap patients, the wound healed uneventfully. Preoperative chest CT scanning was found to be helpful in identifying probable infection of the epicardial leads. In these cases, all hardware had to be removed to achieve resolution of the infection. We concluded that rectus abdominis muscle flaps were helpful in salvaging infected or exposed ICD generators in the absence of infected epicardial leads. (J Card Surg 1993;8:671-677)
\end{abstract}

First reported by Mirowski et al. in 1980,1 the automatic implantable cardioverter defibrillator (ICD) is now recognized as one of the most effective therapies for the prevention of sudden cardiac death in patients with documented sustained ventricular tachycardia or fibrillation. ${ }^{2}$ However, generator pocket infection or erosion occurs in $2 \%$ to $5 \%$ of patients following ICD implantation, and poses a significant clinical problem. ${ }^{3,4}$ Treatment frequently has consisted of generator unit removal accompanied, in some cases, by excision of the lead wires and epicardial patches. Replacement of these devices often must be deferred until the underly-

This work was supported by the Department of Veterans Affairs.

Address for correspondence: Riley S. Rees, M.D., Section of Plastic and Reconstructive Surgery, University of Michigan Hospitals, 1500 East Medical Center Drive, 2130 Taubman Center, Ann Arbor, MI 48109-0340. Fax: (313) 763-0190. ing soft tissue infection has cleared. For patients who depend upon the ICD for treatment of ventricular dysthythmias, even temporary loss of this device represents a potentially lifethreatening complication. In this series, we report a method of salvaging the infected ICD generators using a rectus abdominis muscle flap.

Typically, the ICD electrodes are placed via a thoracotomy or median sternotomy. After being sutured to the epicardium, ICD leads traverse the anterior mediastinum. In the epigastric region, the wires are tunneled subcutaneously onto the anterior abdominal wall where the generator box is located. The generator unit is positioned in a subcutaneous pocket.

Wound complications related to the ICD generator placement can develop either from erosion of the generator box or infection of the generator pocket. The bulk and rigid rectangular shape of the ICD generator box often pro- 
duce thinning of the overlying subcutaneum and dermis. Subcutaneous placement of the generator may create skin necrosis by interrupting dermal perforators from the underlying abdominal wall musculature. ICD leads can also become exposed in a similar fashion; because the wires are only available in one length, excess cable is often coiled within the generator pocket. The resulting wire loops produce pressure points on the skin, leading to skin erosion (Fig. 1). This excess cable also makes removal difficult due to incorporation of the leads into the surrounding scar.

ICD infection can present in a variety of ways. Primary infection of the generator unit is usually characterized by erythema and induration of the overlying soft tissue with or without systemic findings such as fever and chills. Bacterial seeding of the ICD leads and epicardial electrodes may occur secondarily. Infection also results from breakdown of the abdominal ICD pocket, producing contamination of the generator and associated leads. With the pres- ence of a contaminated foreign body, wound healing becomes problematic.

At our institution, the ICD has been utilized in the treatment of ventricular dysrhythmias since 1987. This study examines the acute and longterm wound related complications of this procedure. Specifically, we have sought to analyze the effectiveness of rectus abdominis muscle flaps in salvaging infected or exposed ICD units.

\section{METHODS}

The charts of all patients admitted to the University of Michigan Hospitals with ICD wound complications from 1987 to 1992 were reviewed. Data also were obtained from the Electrophysiology Laboratory records at the University. Patients with ICD infections and those with generator erosion or exposure were admitted to the thoracic surgery service with plastic surgical consultation. Patients who presented with
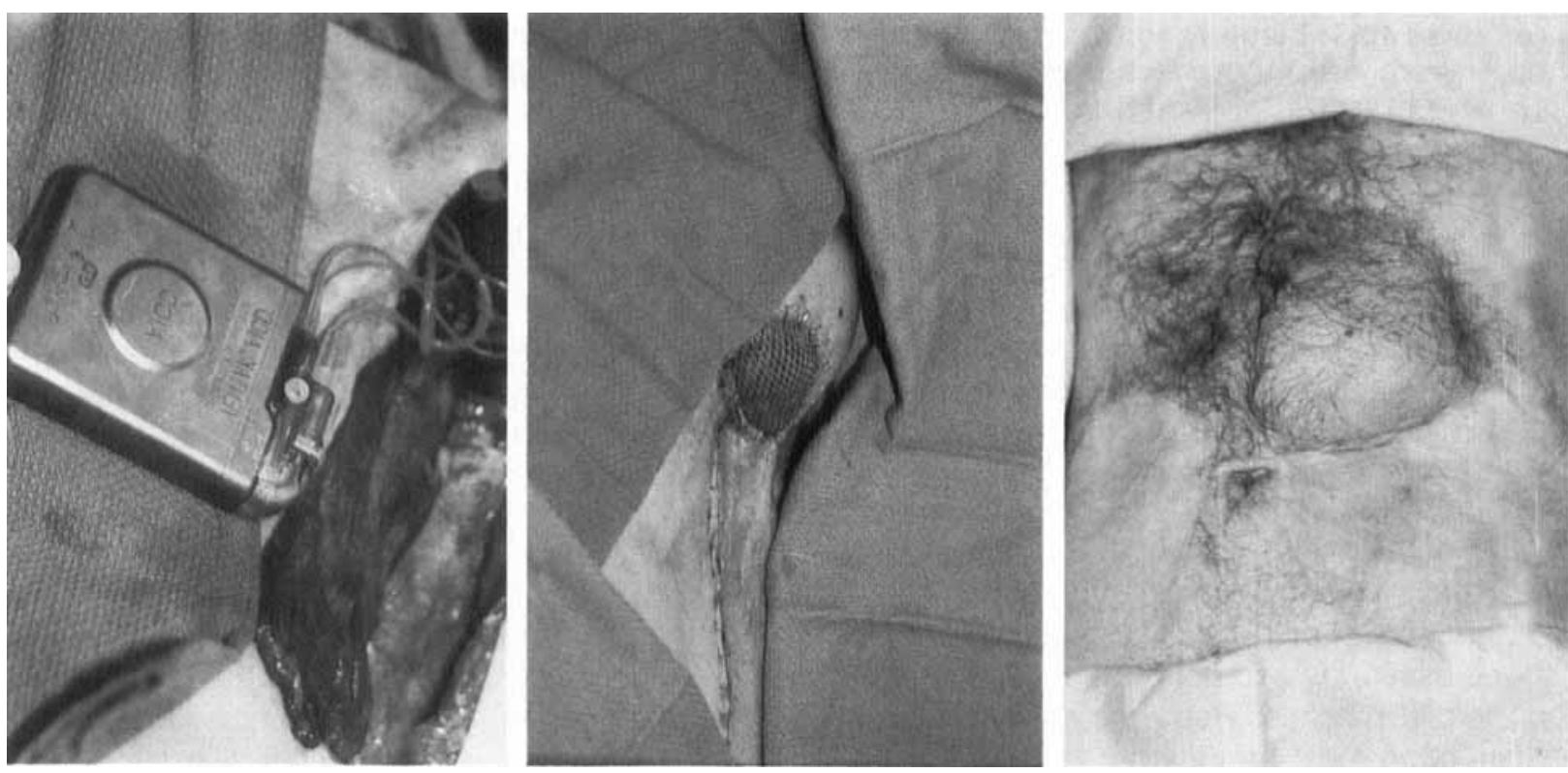

Figure 1. (Left) The large size of the ICD generator necessitated its placement over abdominal fascia below the right costal margin. It was removed and the rectus muscle that is detached from the pubis is next to the generator. Note the coiled wires in the wound. (Center) Thinning of the overlying dermis occurred at pressure points created when the edge of the rectangular generator impinged on the undersurface of the skin. Subcutaneous placement of the generator interrupted the dermal perforators from the underlying abdominal wall musculature and produced pressure necrosis of the subdermal vascular plexus. The skin necrosis required skin grafting to reconstruct the pocket. (Right) Healed wound with skin grafted muscle flap after placement wrapping the generator in muscle. Photograph was taken 3 months after the operation. 
pocket erosion without exposure were scheduled for elective revision. Individuals with exposed or infected ICD units were treated with debridement and generator box removal or muscle flap coverage. Cultures were obtained on all patients with suspected infection. All but one patient were followed postoperatively at the University of Michigan.

In cases with generator pocket infection where bacterial seeding of the epicardial electrodes was suspected, preoperative work-up included a chest computed tomography (CT) scan. Fluid collections identified around the electrode patches were interpreted as presumptive evidence of local infection. Due to the extent of contamination in these cases, ICD salvage was not attempted; the generator box, leads, and patches were removed. If the chest CT scan did not demonstrate evidence of fluid collections at the electrodes, debridement and muscle tlap coverage of the generator pocket was attempted.

Salvage of the generator pocket was carried out as follows: following exposure of the generator, the pocket was decorticated and the wound excised. In most cases, the rectus abdominis muscle was approached through the debrided wound in addition to a vertical or horizontal counter incision over the ipsilateral rectus sheath (Fig. 2). The muscle was mobilized in one of three ways. With the first technique, the rectus was raised from the anterior and posterior fascia, ligating segmental intercostal perforating vessels. Once mobilized, the deep inferior epigastric pedicle was ligated, the insertion divided, and the muscle rotated superiorly on its superior epigastric artery pedicle (Fig. 3B). The ICD generator was relocated in its original pocket and wrapped in the muscle flap. After placement of suction drains, the overlying soft tissue was closed in layers.

The second technique for mobilization of the rectus abdominis preserved the origin, insertion, and major vascular pedicles of the muscle. The rectus sheath was entered via longitudinal incision in the lateral edge of the anterior fascia. A new pocket was created between the muscle and posterior rectus sheath above the arcuate line. After the generator was placed in the pocket, the rectus sheath and superficial layers were closed over Jackson-Pratt drains (Fig. 3A).

The third technique was reserved for patients who had a small body habitus or an oversized ICD generator. In this procedure, a pocket was created beneath the rectus and external oblique muscles. The device was oriented in an oblique fashion in the pocket and the overlying incision closed in layers (Fig. $3 \mathrm{C}$ ).

Postoperatively, all patients received 7 to 10 days of intravenous antibiotics. Patients were followed in the plastic surgery clinic and monitored for recurrent infection and other potential wound complications.
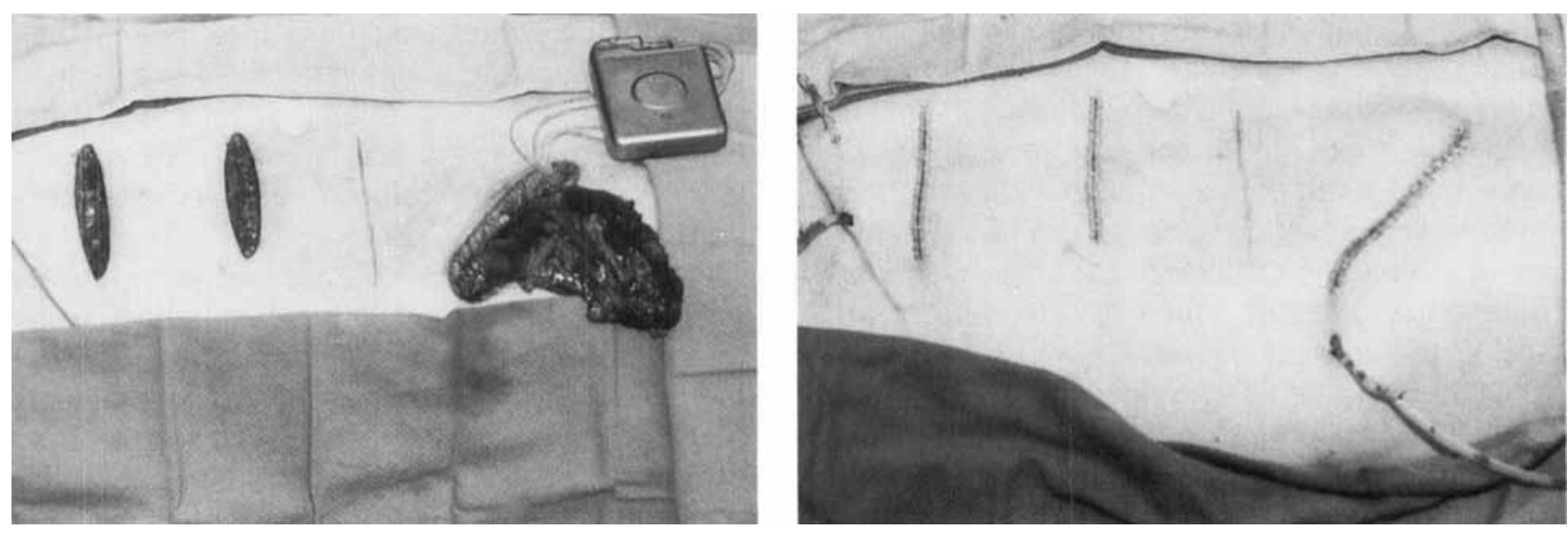

Figure 2. (Left) Rectus abdominis muscle was exposed through either a single vertical or two transverse incisions. The muscle was mobilized from the anterior and posterior rectus sheaths, so that the segmental intercostal perforating vessels and distal attachment could be ligated. (Right) Three parallel incisions used to approach the rectus muscle and closed in layers. These incisions were used in patients where the abdominal skin may have necrosed because of infection on previous scarring. 


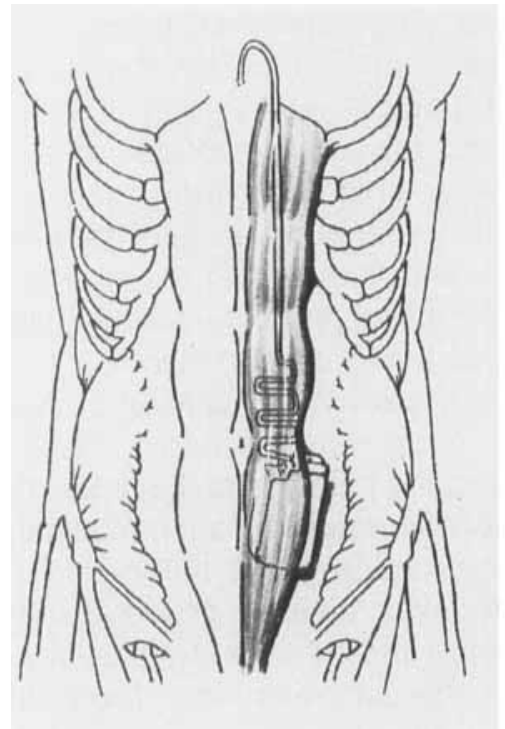

A

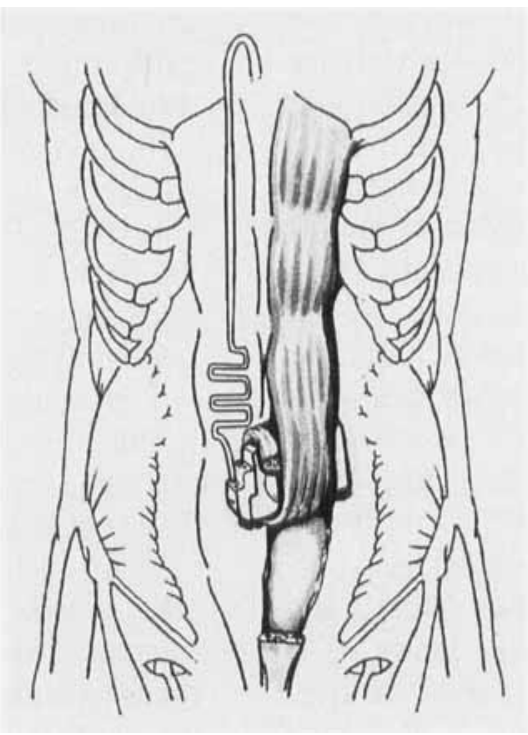

B

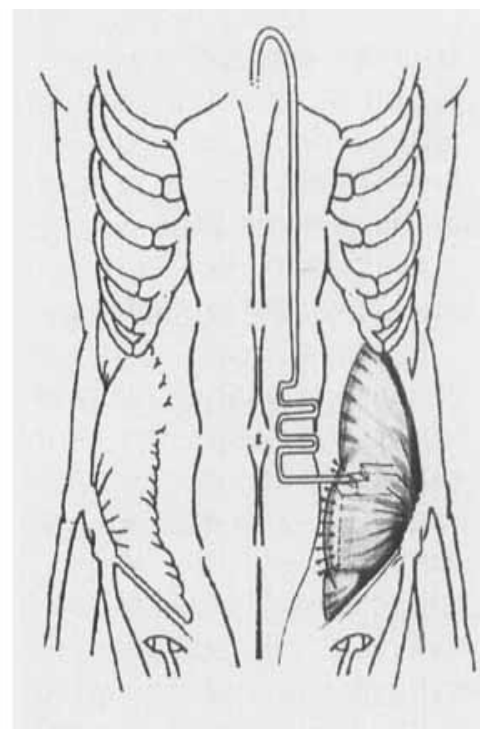

C

Figure 3. (A) The preferred option was to place the generator beneath the rectus muscle. This option was utilized when there was sufficient muscle to cover the generator. This was the simplest and most often used approach. (B) In some patients, the deep inferior epigastric pedicle was ligated, the insertion divided, and the muscle rotated superiorly on its superior epigastric artery pedicle to surround the generation with muscle. This option was necessary in patients with unstable skin overlying the previous pocket site (see Fig. 1). (C) In some cases, the device was too large for the rectus muscle alone and the external oblique was mobilized to position the generator beneath the rectus and external oblique.

\section{RESULTS}

From 1987 through 1992, 412 ICDs were implanted. Seventeen patients developed wound complications. Among those with complications, the median age was 60 years (Table 1). Of the 16 patients who returned to the clinic postoperatively, median follow-up was 13 months. Thirteen patients developed infections with or without generator unit exposure. The patients showed pocket erosion without associated wound infection. One patient had a hematoma around the generator and underwent percutaneous drainage (Table 1). To date, 13 of the 17 patients remain alive.

Of the 13 patients who developed ICD wound infections, cultures were able to identify the causative organism in 11 (Table 1). Coagulase positive Staphylococcus aureus was the most common species $(N=5)$. Three infected patients were treated successfully with ICD removal alone. One of these patients underwent heart transplantation 5 months later, while another required rectus abdominis and pectoralis flaps to close an infected sternum wound. The remaining 10 patients were treated with rectus abdominis muscle flaps to cover the generators. The muscle flap achieved successful closure in 8 of these 10 individuals. The two cases with recurrent infection after debridement and flap closure were later noted to have fluid around the epicardial patches on CT scan, indicating unrecognized infection to the mediastinum. In these cases, infection of the ICD leads necessitated removal of the generator unit, wires, and patches.

In the three patients who developed pocket erosion without wound infection, one was treated with ICD removal and medical management. The two remaining patients underwent rectus abdominis muscle flap coverage and pocket revision. All three individuals recovered uneventfully and suffered no further wound complications (Table 2).

\section{DISCUSSION}

In this series, ICD placement was associated 
TABLE 1

Indications for and Complications of ICD Placement*

\begin{tabular}{|c|c|c|c|c|}
\hline Case No. & Indication & Complication & $\begin{array}{l}\text { Months Prior } \\
\text { to Infection }\end{array}$ & Organism \\
\hline $\begin{array}{l}1 \\
2\end{array}$ & $\begin{array}{l}\text { S/P MI } \\
\text { Sudden death } \\
\text { with inducible VT }\end{array}$ & $\begin{array}{l}\text { Erosion with infection } \\
\text { Erosion with infection }\end{array}$ & $\begin{array}{r}25 \\
5\end{array}$ & $\begin{array}{l}\text { Coag (+) Staph } \\
\text { Corynebacteria, Strep }\end{array}$ \\
\hline 3 & S/P MI, Sudden death & Infection & 1 & Coag (+) Staph \\
\hline 4 & CABG, Sudden death & Infection & 2 & No growth \\
\hline 5 & Sudden death & Infection & 4 & Coag (-) Staph \\
\hline 6 & CABG with recurrent VT & Infection & 1 & Coag (t) Staph \\
\hline 7 & CABG with sudden death & Erosion without infection & 54 & NA (2) \\
\hline 8 & S/P MI with inducible VT & Infection & 13 & Coag (t) Staph \\
\hline 9 & Sudden death & Hematoma & 1 & Coag (+) Staph \\
\hline 10 & CABG with VT & Erosion without infection & 13 & No growth \\
\hline 11 & CABG with sudden death & Erosion without infection & 2 & No growth \\
\hline 12 & Sudden death & Infection & 4 & Morganella \\
\hline 13 & S/P MI, Sudden death & Erosion without infection & 36 & Pseudomonas \\
\hline 14 & Syncope, VT & Erosion without infection & 1.5 & Pseudomonas \\
\hline 15 & Sudden death & Infection & 1.0 & No growth \\
\hline 16 & $\mathrm{VT}$ & Infection & 3.0 & Staph Coag (+) \\
\hline 17 & Sudden death & Infection & 2.5 & No growth \\
\hline
\end{tabular}

*The interval between placement and complications is noted in 17 cases. CABG = coronary artery bypass graft; Coag $(+) /(-)=$ coagulase positive/negative; $S / P=$ status post; Staph = Staphylococcus; Strep = Streptococcus; VT = ventricular tachycardia.

TABLE 2

Outcome of 17 Patients After Removal of the ICD

\begin{tabular}{|c|c|c|c|c|c|c|}
\hline $\begin{array}{l}\text { Case } \\
\text { No. }\end{array}$ & Procedure & Alive & $\begin{array}{l}\text { ICD in } \\
\text { Place }\end{array}$ & Flre* & $\begin{array}{l}\text { Func- } \\
\text { tioningt }\end{array}$ & Follow-Up \\
\hline $\begin{array}{r}1 \\
2 \\
3 \\
4 \\
5 \\
6 \\
7 \\
8 \\
9 \\
10 \\
11 \\
12 \\
13 \\
14 \\
15 \\
16 \\
17\end{array}$ & $\begin{array}{l}\text { Debridement } \\
\text { Debridement/Rectus flap } \\
\text { Debridement/Rectus flap } \\
\text { Debridement/Rectus flap } \\
\text { Removal and debridement } \\
\text { Removal and debridement } \\
\text { Removal and debridement } \\
\text { Debridement/Rectus flap } \\
\text { Hematoma drained } \\
\text { Debridement/Rectus flap } \\
\text { Debridement/Rectus flap } \\
\text { Debridement/Rectus flap } \\
\text { Debridement/Rectus flap } \\
\text { Debridement/Rectus flap } \\
\text { Pocket revision } \\
\text { Rectus abdominis } \\
\text { Rectus abdominis }\end{array}$ & $\begin{array}{l}\text { Yes } \\
\text { Yes } \\
\text { Yes } \\
\text { Yes } \\
\text { Yes } \\
\text { No } \\
\text { Yes } \\
\text { Yes } \\
\text { Yes } \\
\text { No } \\
\text { Yes } \\
\text { Yes } \\
\text { No } \\
\text { No } \\
\text { No } \\
\text { No } \\
\text { Yes }\end{array}$ & $\begin{array}{l}\text { No } \\
\text { Yes } \\
\text { Yes } \\
\text { Yes } \\
\text { No } \\
\text { No } \\
\text { No } \\
\text { No } \\
\text { Yes } \\
\text { Yes } \\
\text { No } \\
\text { Yes } \\
\text { Yes } \\
\text { Yes } \\
\text { Yes } \\
\text { Yes } \\
\text { Yes }\end{array}$ & $\begin{array}{l}\text { No } \\
\text { Yes } \\
\text { Yes } \\
\text { Yes } \\
\text { No } \\
\text { No } \\
\text { No } \\
\text { No } \\
\text { Yes } \\
\text { No } \\
\text { No } \\
\text { Yes } \\
\text { Yes } \\
\text { No } \\
\text { No } \\
\text { Yes } \\
\text { Yes }\end{array}$ & $\begin{array}{l}\text { No } \\
\text { Yes } \\
\text { Yes } \\
\text { Yes } \\
\text { No } \\
\text { No } \\
\text { No } \\
\text { No } \\
\text { Yes } \\
\text { Yes } \\
\text { No } \\
\text { Yes } \\
\text { Yes } \\
\text { Yes } \\
\text { Yes } \\
\text { Yes } \\
\text { Yes }\end{array}$ & $\begin{array}{l}\text { Heart transplant } 11 / 31 / 91 \\
\text { Medical } R x \text { includes amiodarone } \\
\text { Medical } R x \\
\text { Medical } R x \\
\text { Medical } R x \\
\text { Medical } R x \text { includes amiodarone } \\
\text { No medical therapy } \\
\text { Medical } R x \\
\text { No medical therapy } \\
\text { No Medical therapy } \\
\text { Reinfected/In-House } \\
\text { Medical } R x \text { includes amiodarone } \\
\text { Ischemic cardiomyopathy } \\
\text { Medical } R x \\
\text { Medical } R x \\
\text { Medical } \mathrm{Rx} \text { includes amiodarone } \\
\text { Medical } R x\end{array}$ \\
\hline
\end{tabular}

"ICD fired after placement; IICD functioning at the time of the report.

with wound complications resulting from infection, erosion, and hematoma. Although explantation of the device was necessary in 6 of 17 cases to achieve wound closure, the device was salvaged in the remaining 11 patients. In treating these complications, ICD salvage is desirable for a variety of reasons, including the time and expense required to replace epicardial patches, leads, and generators. Also, medical alternatives, such as amiodarone, for treatment of ventricular tachycardias are associated with significant complications, including pulmonary fibrosis. 5

Wound complications with cardiac devices 
have been treated with a variety of surgical techniques, including removal and placement at a new site ${ }^{4}$ pocket debridement and closed irrigation, 6 skin flap rotation, 7 and submuscular pocket placement. 8 The presence of foreign bodies, such as a large ICD device, makes wound closure and eradication of the underlying infection especially difficult. All three series taken together suggest that salvage of the ICD unit and leads has remained problematic in the presence of infection.

Muscle flaps have been effectively used in the treatment of infected wounds with foreign bodies. ${ }^{9}$ Unlike skin flaps, muscle flaps provide effective coverage of wounds containing 105 bacteria per gram of tissue. 10 With abundant new blood supply, this durable tissue provides stable wound closure that is highly resistant to infection. Muscle flaps have been used successfully in the management of infected and exposed prostheses in a variety of clinical settings. 9,10 The rectus abdominis muscle flap has been particularly effective in difficult chest wall wounds, such as the treatment of infected chest wall prostheses ${ }^{11}$ and sternal infections. 12 These studies have established that infected foreign bodies and poorly vascularized, nonhealing wounds can be effectively treated with aggressive debridement and muscle flap closure. Our experience with ICD wound complications confirms these findings.

In addition to the use of muscle flaps, another important factor in the successful diagnosis and treatment of ICD infections is the management of the leads and epicardial patches. Not all patients in this series underwent preoperative CT scans to evaluate these components of the device. Unfortunately, neither patient noted to have recurrent wound infections after rectus abdominis ICD salvage were scanned prior to surgical salvage. After the diagnosis of recurrent infection, chest $C T$ evaluation was obtained, which revealed fluid collections around the epicardial patches. In both cases, localized patch infection was found when the device and leads were removed and resolved thereafter. As a result of these failures, all subsequent patients in our series underwent preoperative chest CT scanning. If fluid was identified, all ICD components were removed at the time of surgery. After institution of this protocol, no further recurrences of infection were noted.
Presence of "peripatch" abscesses on CT scan constituted a contraindication to muscle flap salvage of the ICD.

Finally, several factors may play a role in the prevention of ICD wound complications. First, initial placement of the generator unit in a submuscular pocket may be indicated in patients with minimal subcutaneous tissue or individuals predisposed to wound complications. The latter subgroup includes insulin dependent diabetics or long-term systemic steroid therapy. Patients exhibiting early signs of skin erosion should be considered for immediate revision with rectus muscle flap closure. Hopefully, this problem will resolve with smaller generators and transvenous lead placement.

Acknowledgments: Technical support was provided by Nancy Werkema and Susan Richardson.

\section{REFERENCES}

1. Mirowski M, Reid PR, Mower MM, et al: Termination of malignant ventricular arrhythmias with an implantable defibrillator in human beings. $N$ Engl J Med 1980;303:322-324.

2. Manolis AS, Rastegar H, Estes NA: Automatic implantable cardioverter defibrillator: Current status. J Am Med Assoc 1989;262:1362-1368.

3. Almassi GH, Olinger GN, Trap PJ, et al: Delayed infection of the automatic implantable cardioverter defibrillator: Current recognition and management. J Thorac Cardiovasc Surg 1988;95: 908-911.

4. Mansour KA, Kauten JR, Hatcher CR Jr: Management of the infected pacemaker: Explanation, sterilization, and reimplantation. Ann Thorac Surg 1985;40:617-619.

5. Huang SK, Tan de Guzman WL, Chenarides JG, et al: Effects of long-term amiodarone therapy on the defibrillation threshold and the rate of shocks of the implantable cardioverter-defibrillator. Am Heart J 1991;122:720-727.

6. Hurst LN, Evans HB, Windle B, et al: The salvage of infected cardiac pacemaker pockets using a closed irrigation system. PACE 1986;9: 785-792.

7. Coburn RJ, Blank HL, Campbell RM: Covering an exposed pacemaker: Case report. Plast $\mathrm{Re}$ constr Surg 1972;50:622-625.

8. Fayman MS, Chait LA, Orak F: A subpectoral pocket in the management of a patient with impending extrusion of a pulse generator. Plast Reconstr Surg 1986;78:182-185.

9. Cruz NI, Canario QM: Muscle flaps in the management of vascular grafts in contaminated wounds: An experimental study in dogs. Plast Reconstr Surg 1988;82:480-485.

10. Murphy RC, Robson MC, Heggers JP, et al: The 
effect of microbial contamination on musculocutaneous and random flaps. J Surg Res 1986;41: 75-80.

11. Wiebke EA, McDonald HD, Pass HI: The infected chest wall prosthesis: Management of excision and contralateral transverse rectus ab- dominis musculocutaneous flap. Ann Thorac Surg 1987; 44:544-545.

12. Nahai F, Rand RP, Hester TR, et al: Primary treatment of the infected sternotomy wound with muscle flaps: A review of 211 consecutive cases. Plast Reconstr Surg 1989;84:434-441. 